\title{
Comparison of an LCA and LCC for façade renovation strategies designed for change
}

\author{
Lisa Van Gulck ${ }^{1, *}$ Stijn Van de Putte ${ }^{1}$, Nathan Van Den Bossche ${ }^{1}$, Marijke Steeman ${ }^{1}$ \\ ${ }^{1}$ Ghent University, Faculty of Engineering and Architecture, Department of Architecture and Urban Planning, Sint Pietersnieuwstraat \\ 41 B4, 9000 Ghent, Belgium
}

\begin{abstract}
This paper examines the environmental and financial impact of façade renovation strategies designed for change and how taking into account each of these aspects will lead to different renovation decisions. In a first part of the paper the optimal construction method for different façade renovation strategies is searched from the environmental point of view. This is done through life cycle analysis (LCA). In a second part of the paper the financial impact of the results obtained with LCA is determined. This is done with life cycle costing (LCC). The results show that although both LCA and LCC are life cycle studies that follow similar principles and boundaries this does not mean that LCA and LCC based decisions will coincide. For the environmental score the operational energy of a building has the largest impact and energy efficiency measures will often be beneficial. For the financial cost the investment cost is the most important impact and energy efficiency measures will only pay off to a certain extent. Decisions that are based solely on the financial cost may thus lead to sub-optimal solutions from an environmental point of view.
\end{abstract}

\section{Introduction}

A large part of the Belgian residential building stock is outdated and does not comply with the present energy standards, resulting in a huge environmental impact. It's neither feasible nor sustainable to demolish all these buildings and to replace them with new ones. A viable solution is the energetic renovation of the existing buildings [1]. However, to really assess the entire environmental impact of a building it is important to look further than the operational phase and to take the whole life cycle of a building into account. This is possible with life cycle analysis (LCA).

In an ideal world renovation decisions would be made solely from an environmental point of view. In reality the financial aspect will be the most determining parameter. To calculate the true financial cost of a building it is again necessary to look further than one life phase and take the costs occurring over all life phases of the building into account. This is done through life cycle costing (LCC).

In this paper both the environmental and financial impact of renovation strategies are examined. Taking into account both these aspects results in a more comprehensive approach for assessing renovation strategies. It will show how both aspects relate to each other and how they influence renovation decisions $[2,3,4]$. The research will be implemented on the case study Drie Hofsteden Building $I V$, an apartment building in Kortrijk of which the renovation was concluded in 2019. Because for high rise buildings insulating the façade has the largest impact on the energy losses, the focus of the research is façade renovation strategies. The research concentrates on construction methods based on the design for change (DFC) strategy. The DFC strategy acknowledges the need of evolving buildings by looking at the possibilities of adaption and reuse of a building and building components during and at the end of their life span. The goal is to prolong their life span as much as possible by conceiving them as dynamic elements, i.e. elements that will evolve over time. Constructions that comply with the DFC strategy will be referred to as 'dynamic' further in this research. The DFC strategy is a key principle in evolving towards a circular construction sector.

\section{Methodology}

The research consists of two sub-studies. First an LCA study will be performed to find the façade renovation strategies that are optimal from an environmental point of view. To examine how these environmentally optimal solutions score financially, an LCC study is conducted in a next step. The goal is to examine how LCA and LCC relate to each other. What are their differences and similarities and how will these affect the optimal renovation strategies?

\footnotetext{
* Corresponding author: lisa.vangulck@,ugent.be
} 


\subsection{Façade renovation strategies}

The existing façade of Building IV is an uninsulated brick cavity wall $\left(\mathrm{U}=1,76 \mathrm{~W} / \mathrm{m}^{2} \mathrm{~K}\right)$ with windows of single glazing and a wooden window frame with metal finishing $\left(U_{\mathrm{w}}=5 \mathrm{~W} / \mathrm{m}^{2} \mathrm{~K}\right)$. Since there are no impacts or costs generated from this structure it will not be simulated. All comparisons will be in relation to the original building before renovation, in this research further referred to as the 'Baseline scenario'(BL).

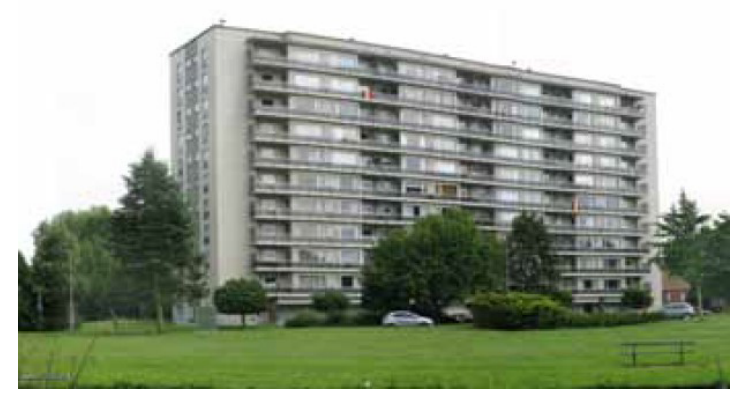

Fig. 1. Building IV before renovation.

Table 1 gives an overview of the façade renovation strategies and their dynamic construction method that are considered in this study. Although ETICS does not qualify as a dynamic construction method (use of mortar for the fixation of the insulation and plaster finishing), this strategy is researched because it is the renovation strategy that was actually executed for Building IV. An attempt to develop a dynamic version of ETICS is made by replacing the mortar by a mechanical connection of PVC-profiles [5]. It was however not possible to find a dynamic alternative for the plaster finishing within the ETICS system. For this a switch to the strategy External wall insulation is necessary.

Table 1. Façade renovation strategies.

\begin{tabular}{|l|l|}
\hline Strategy & Construction method \\
\hline ETICS & $\begin{array}{l}\text { - Standard } \\
\text { - Dynamic version }\end{array}$ \\
\hline External wall insulation & Ventilated façade system \\
\hline Internal wall insulation & Timber stud wall \\
\hline Cavity wall insulation & Blown in insulation \\
\hline
\end{tabular}

\subsection{Research steps LCA study}

In a first part of the LCA study an optimal wall construction, in terms of connections, materials and insulation thickness, is searched for every façade renovation strategy. Once the optimal wall construction per strategy is found, the optimal results are compared to show how the different strategies score environmentally relative to each other. All these research steps are simulated for $1 \mathrm{~m}^{2}$ wall construction. In a last step of the LCA research the different optimal wall constructions will be combined with different windows in order to compose a façade and to examine how the replacement of the window and/or the adaption of the wall construction influences the environmental impact of the façade. This is simulated for one apartment unit. Since the façades of all apartment units are similar these results are valid for most units of the building.

\subsection{Research steps LCC study}

The main question is how the results of the LCC study relate to the results of the LCA study. This will be researched by executing the intermediate steps of the LCA study again but this time for the LCC study. The aspects or solutions that are compared in the first substudy through LCA will now be compared for LCC.

\subsection{Boundary conditions}

Both LCA and LCC are life cycle studies and are similarly structured. In order for the results of the two studies to be comparable the same boundary conditions need to be applied. This means the same functional unit and lifespan must be used in both studies. For this research a life span of 60 years is chosen. The life cycle phases should be equivalent, but not necessarily the same as different processes may have different relevance from the environmental and financial viewpoint [6]. Table 2 shows the typical phases of the life cycle of a building. The phases in italic will not be taken into account for the calculations performed in this research.

Table 2. Life cycle phases of a building.

\begin{tabular}{|c|c|}
\hline $\begin{array}{c}\text { LCA (environmental } \\
\text { impact) }\end{array}$ & LCC (financial costs) \\
\hline $\begin{array}{ll}\text { Initial: } \\
-\quad \text { Exploitation and } \\
\quad \text { production of materials } \\
-\quad \text { Transport to site } \\
-\quad \text { Construction } \\
\end{array}$ & \begin{tabular}{ll}
\multicolumn{2}{l}{ Initial: } \\
$-\quad$ Material \\
$-\quad$ Transport to site \\
$-\quad$ Labor
\end{tabular} \\
\hline $\begin{array}{ll}\text { Use: } \\
-\quad \text { Operational energy } \\
-\quad \text { Replacements } \\
-\quad \text { Maintenance } \\
\end{array}$ & \begin{tabular}{ll}
\multicolumn{2}{l}{ Use: } \\
$-\quad$ Operational energy \\
$-\quad$ Replacements \\
$-\quad$ Maintenance \\
\end{tabular} \\
\hline $\begin{array}{l}\text { End-of-life: } \\
-\quad \text { Deconstruction } \\
-\quad \text { Transport to end-of-life } \\
\quad \text { treatment } \\
-\quad \text { End-of-life treatment }\end{array}$ & $\begin{array}{l}\text { End-of-life: } \\
-\quad \text { Deconstruction } \\
-\quad \text { Transport to end-of-life } \\
\quad \text { treatment } \\
-\quad \text { End-of-life treatment }\end{array}$ \\
\hline
\end{tabular}

The construction and maintenance phase are not simulated for the LCA study because not enough reliable information is available. These phases have a very small share in the environmental impact and will not significantly alter the results. For the financial cost there will be an important impact of these phases and therefore they need to be included [7-9].

For the calculation of the operational energy only transmission losses and infiltration losses (both dependent on the performance of the building façade) are taken into account. All other energy (for hot water, household appliances, etc.) is assumed equal for the different scenarios and does not need to be modelled, since with comparisons only the differences are relevant. 
The energy balance is calculated using the monthly quasi-steady state method, the method used in the framework of the Belgian EPBD regulations. For the calculations an in-house developed software tool is used [10].

For both studies the end-of-life phase is not taken into account because of the uncertainties connected to the future. The inclusion of this phase would require an extensive scenario study. However, dynamic constructions have a high reuse and high-quality recycling potential and these possible end-of-life gains should not be neglected. Although these gains aren't quantified in this study, it is important to qualify them. It is assumed that the obtained results will be more beneficial as a construction scores better on the DFC criteria.

\section{LCA study}

The LCA study is conducted with the life cycle software SimaPro and the Ecoinvent 3.3 database is used. The impact method used to classify the environmental impact is ReCiPe 2008 [11]. The LCA results will be expressed in a single score (i.e. the environmental score expressed in points) to make them easily understandable and comparable with the LCC results.

\subsection{Optimal wall constructions}

For every façade renovation strategy an optimal wall construction is searched in terms of connections, materials and insulation thickness. After the construction method that scores best on the DFC criteria for the façade renovation strategy is selected (Table 1), the optimal material combinations are analyzed. First the most relevant insulation materials (and the accompanying supporting structure) that can be used with the dynamic construction method are selected. The solution that gives the lowest environmental score is chosen. In a next step the finishing layers that are compatible with the chosen insulation material and construction method are selected and again compared from the environmental perspective. This way the wall construction with the best environmental score is assembled per renovation strategy. Figure 2 gives an overview of the different options per renovation strategy that are analyzed. For the analysis of the optimal material combinations the U-values of the compared wall constructions within a renovation strategy are the same, which means their related operational energy is also the same and does not need to be simulated. The environmental score thus only relates to the impact of added materials for the renovation strategy and not to the operational energy use. The options that give the lowest environmental impact for that strategy are marked (E). E.g. for external wall insulation the optimal construction is a ventilated façade system with hard insulation (PUR) and a façade cladding of fiber cement panels.

For ETICS the standard and dynamic version have a similar environmental score and both construction methods shall be included in next research steps.
However, with the dynamic version only constructions up to $14 \mathrm{~cm}$ insulation can be constructed without consulting the manufacturer [5]. This limitation will be taken into account in the next steps and no other insulation thicknesses will be combined with this dynamic version of ETICS.

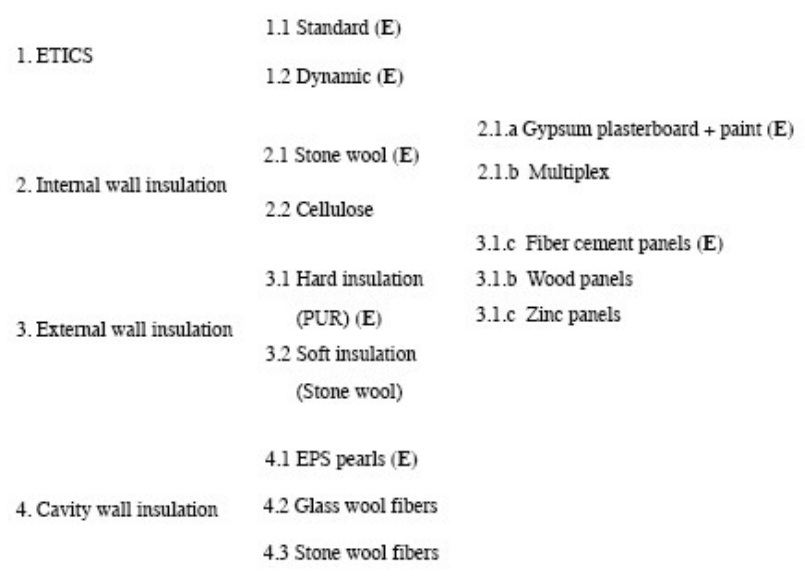

Fig. 2. Overview of materials analyzed in renovation strategies.

\subsubsection{Optimal insulation thickness}

For each of the optimal constructions a corresponding optimal insulation thickness is searched. This is the thickness at which point the environmental impact of adding extra insulation will not be compensated anymore by the obtained energy savings, and thus the thickness from which the environmental score will start to increase again. The variation in insulation thickness does not only change the amount of insulation of the construction but also the dimensions of supporting structure. The research of the optimal insulation thickness gives an indication of the orders of magnitude that are considered environmentally optimal and these can be compared with the maximum installed insulation thicknesses by manufacturers and the Flemish EPB requirement of $\mathrm{U}_{\max }=0,24 \mathrm{~W} / \mathrm{m}^{2} \mathrm{~K}$ for outer walls.

For the standard ETICS system the optimal insulation thickness is $47 \mathrm{~cm}\left(\mathrm{U}=0,08 \mathrm{~W} / \mathrm{m}^{2} \mathrm{~K}\right)$, which is above the maximum installed thickness of $40 \mathrm{~cm}$ EPS $[12,13]$. The same conclusion can be made for the External wall insulation where an optimal thickness of $36 \mathrm{~cm}$ PUR $\left(\mathrm{U}=0,08 \mathrm{~W} / \mathrm{m}^{2} \mathrm{~K}\right)$ is found and the maximum installed thickness is $28 \mathrm{~cm}$ [14]. These very thick optimal insulation thicknesses with extremely low U-values raise the question if it is even relevant for the EPB requirement to evolve to such 'environmental optimal' values. It is clear that from the environmental point of view the increase in insulation thickness is compensated by the operational energy savings but are these environmentally optimal insulation thicknesses financially affordable?

For the Internal wall insulation the optimal thickness is $20 \mathrm{~cm}$ stone wool $\left(\mathrm{U}=0,44 \mathrm{~W} / \mathrm{m}^{2} \mathrm{~K}\right)$. Although $20 \mathrm{~cm}$ internal insulation takes up a lot of the living space, still only high U-values are reached. A large quantity of materials are added without being able to realize 
sufficient energy savings. This leads to high environmental impacts and to optimal insulation thicknesses corresponding with low U-values. It is clear that this dynamic construction method of stone wool between timber studs does not offer an attractive renovation strategy and another dynamic construction method should be developed for Internal wall insulation. For the Cavity wall insulation no optimal thickness is searched since for this strategy there is no other solution than completely filling up the cavity of Building IV $(9 \mathrm{~cm})$.

\subsection{Comparison wall constructions}

In the next step the optimal wall constructions, composed from the results of the two previous steps, are compared amongst each other from the environmental perspective. For the strategies where the optimal insulation thickness is higher than the maximum installed thickness, the latter is used. The actual executed insulation thickness $(27 \mathrm{~cm})$ of the ETICS system applied to Building IV is also simulated and compared. Figure 3 shows the environmental score of the different wall constructions after a life span of 60 years. The environmental score consists of the material impact, this is the material added for the renovation strategy, and the energy impact from the operational energy use. The wall constructions are depicted in relation to the Baseline scenario. This illustrates which energy savings are realized by which material addition compared to the original situation without material addition.

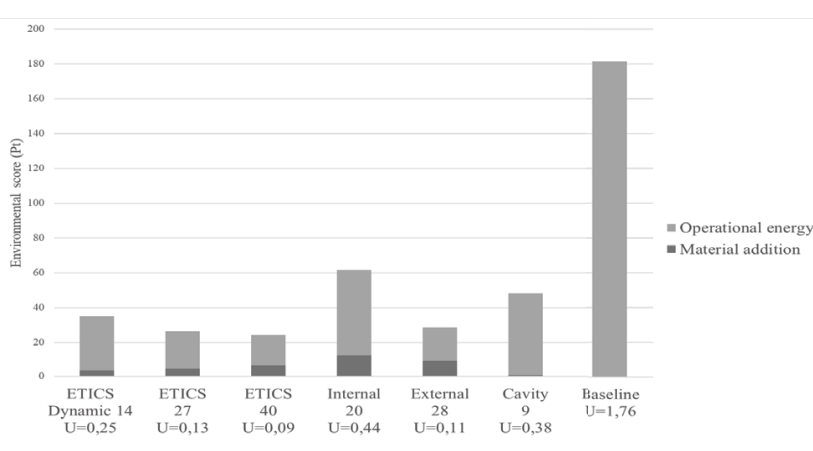

Fig. 3. Environmental score of wall constructions after 60 years.

Figure 3 shows that ETICS $40 \mathrm{~cm}$ has the best environmental score. Internal wall insulation scores the worst. It has the highest material and energy impact. Although Cavity wall insulation has the second worst score, it is the strategy where it's possible to achieve significant energy savings with only a small material addition $(0,7 \mathrm{pt}$ - not even visible on the graph). The actual executed renovation of Building IV (ETICS $27 \mathrm{~cm}$ ) has the second best score. The difference with the best scoring wall construction, which is the same strategy, is relatively small and this raises the question if it is really worth it to invest in $13 \mathrm{~cm}$ extra EPS. $27 \mathrm{~cm}$ EPS is already enough for Building IV to comply with the NZEB requirements. In the LCC study it will become clear what it financially means to go from ETICS 27 to the environmental optimum ETICS 40.

Although ETICS 40 has the lowest environmental score, it is important to remember that ETICS does not qualify as a dynamic solution. Therefore its end-of-life gains will be much lower than the other dynamic constructions. The inclusion of the end-of-life gains could have changed the ranking of the wall constructions with ETICS no longer being the best strategy. The best scoring dynamic wall construction is External wall insulation.

Figure 3 clearly shows that for all environmental scores of the wall constructions the energy impact has a higher share than the material impact. It is therefore a first important step to reduce the operational energy of a building. This conclusion however, may not lead to the idea that the material choice is of inferior importance. This research shows that there are different ways to achieve energy savings and that a careful consideration of the used materials is always necessary.

\subsection{Optimal façade construction}

For the last step of the LCA research windows and wall constructions will be combined for the composition of the façade. First the environmental impact of single, double and triple glazing is examined. One apartment unit is simulated with three different windows: single, double and triple glazing all with a PVC window frame, without changing the wall construction. These simulations show that a window with triple glazing has the best environmental impact. The higher material impact is compensated by the lower energy use and this results in an overall lower environmental score. With the transition of single $(7,11 \mathrm{kPt})$ to double $(3,13 \mathrm{kPt})$ glazing the environmental score is halved. The difference in environmental score between double and triple $(2,65 \mathrm{kPt})$ glazing is far less significant.

Different windows and wall constructions are combined to compose a façade and to examine how the replacement of the window and/or the adaption of the wall construction influences the environmental score of the façade. Should one have priority over the other when renovating? Table 3 gives an overview of the windows and wall constructions that will be part of the combinations. Again the Baseline scenario is the basis for the comparison and the actual executed renovation (ETICS $27 \mathrm{~cm}+$ windows with triple glazing and aluminum window frames) is also simulated.

Table 3. Window and wall constructions that are used for combinations.

\begin{tabular}{|l|l|}
\hline Window & Wall construction \\
\hline Baseline window (BLwindow) & Baseline scenario \\
\cline { 2 - 2 } & Internal wall insulation \\
\cline { 2 - 2 } Double glazing + PVC frame (2xPVC) & External wall insulation \\
\cline { 2 - 2 } Triple glazing + PVC frame (3xPVC) & ETICS $40 \mathrm{~cm}$ \\
\cline { 2 - 2 } & Cavity wall insulation \\
\hline
\end{tabular}


Figure 4 shows the environmental scores of the different window-wall combinations. Logically the combination of the best scoring wall construction (ETICS 40) with the best scoring window $(3 \mathrm{xPVC})$ gives the best environmental score and vice versa. It seems that the most extensive renovation (where the lowest U-values are reached) has the best environmental score. This is because of the high share the energy impact has in the environmental score. Environmentally it will pay off to invest in energy saving measures because the extra material impact that is needed for the investment will be compensated by the lower energy impact. This was also concluded based on Figure 3. It will be interesting to verify if this is also the case from the financial point of view.

There is no clear-cut answer whether it is better to replace the window or the wall construction. This is dependent on the specific window and wall construction. It is however clear that the replacement of the window and wall is the best solution since these scenarios all score significantly better than when only one of the two is changed.

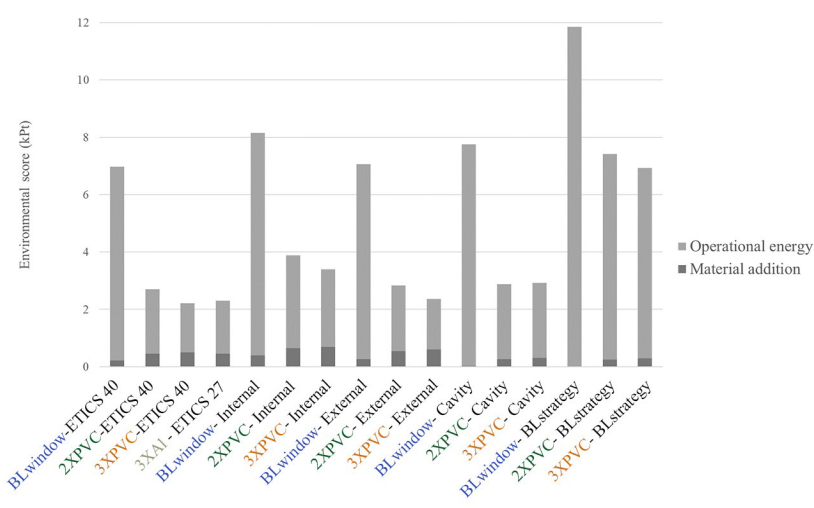

Fig. 4. Environmental score of façade renovation strategies (wall + window).

\section{LCC study}

The Net Present Value (NPV) is the main method to calculate the life cycle cost and is the method used in this research [15]. The NPV is the sum of the initial investment cost and the future costs occurring over the life span of the building. These future costs need to be discounted to the year of investment (year zero) in order to be able to be added to the initial costs. This research works on a micro-economic level, taking into account prices as paid by the end consumer (including taxes). Subsidies are not taken into account to make the results less dependent on specific policy measures.

$$
N P V=C_{I}+C_{E}+C_{M}+C_{R}
$$

$\mathrm{C}_{\mathrm{I}}$ Investment cost

$\mathrm{C}_{\mathrm{E}}$ Operational energy cost

$\mathrm{C}_{\mathrm{M}}$ Maintenance cost

$\mathrm{C}_{\mathrm{R}}$ Replacement cost

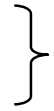

Future costs
Discounting is implemented through the discount rate (d) and can be described as the act of determining the present value of future cash flows. The discount rate is often assumed to be equal to the interest rate for bank loans.[9] Based on the long term interest rate specified in the report Economic prospects 2019-2024 of the Federal Planning Bureau Belgium a real discount rate of $1,8 \%$ is used for the LCC calculations in this research [16].

Energy prices often don't change at the same rate as the general inflation rate. To take this into account a growth rate $(\mathrm{g})$ has to be defined to reflect the different evolution of energy prices over time. [9] Based on the report The Belgian energy landscape by 2050: an outlook assuming no changes in policy of the Federal Planning Bureau Belgium a real growth rate of $1,6 \%$ is taken for the calculations [17].

The main source used to obtain construction costs is the ASPEN price dataset [18]. This database is valid for the Belgian context and contains all building related costs (i.e. labor, material and indirect costs like transport and equipment). The prices in the dataset are without VAT. For renovation and replacement works a VAT of $6 \%$ is used. Only maintenance costs that are relevant for illustrating the difference between different strategies are taken into account.

The heating of Building IV is supplied by a central gas condensing boiler. The average price that was charged to the users of natural gas (including all costs) in the first half of 2019 can be found in the Eurostat table Gas prices for household consumers [19]. Based on this information a price of $0,0496 € / \mathrm{kWh}$ is used to calculate the operational energy costs in this study.

\subsection{Optimal wall constructions}

For every façade renovation strategy the optimal wall construction is searched again but this time from the financial viewpoint. Figure 5 gives an overview of the different options per renovation strategy. The options that give the lowest environmental score (E) and financial cost (F) are indicated. The figure shows that in some cases environmental and financial based decisions coincide and for others not. This illustrates that at times, with the right information, decisions that are environmentally and financially beneficial can be made. 


\begin{tabular}{|c|c|c|}
\hline \multirow{2}{*}{ 1. ETICS } & \multicolumn{2}{|l|}{1.1 Standard $(\mathbf{E})(\mathbf{F})$} \\
\hline & \multicolumn{2}{|l|}{ 1.2 Dynamic (E) } \\
\hline \multirow{3}{*}{ 2. Internal wall insulation } & \multirow[b]{2}{*}{2.1 Stone wool $(\mathbf{E})(\mathbf{F})$} & 2.1.a Gypsum plasterboard + paint (E) \\
\hline & & 2.1.b Multiplex (F) \\
\hline & 2.2 Cellulose & \\
\hline \multirow{5}{*}{ 3. External wall insulation } & & 3.1.c Fiber cement panels $(\mathbf{E})(\mathbf{F})$ \\
\hline & 3.1 Hard insulation & 3.1.b Wood panels \\
\hline & $($ PUR) (E) (F) & 3.1.c Zinc panels \\
\hline & 3.2 Soft insulation & \\
\hline & (Stone wool) & \\
\hline \multirow{3}{*}{ 4. Cavity wall insulation } & 4.1 EPS pearls $(\mathbf{E})$ & \\
\hline & \multicolumn{2}{|l|}{ 4.2 Glass wool fibers (F) } \\
\hline & \multicolumn{2}{|l|}{4.3 Stone wool fibers } \\
\hline
\end{tabular}

Fig. 5. Overview of materials analyzed in renovation strategies. 4.1.1 Optimal insulation thickness

The LCA study showed that extremely high insulation thicknesses are environmentally optimal for some renovation strategies. The optimal insulation thickness is simulated in the LCC study to research if from the financial viewpoint also such large thicknesses will be achieved.

The LCC study results in following optimal insulation thicknesses: $15 \mathrm{~cm}$ EPS $\left(\mathrm{U}=0,23 \mathrm{~W} / \mathrm{m}^{2} \mathrm{~K}\right)$ for ETICS, $12 \mathrm{~cm}$ PUR $\left(\mathrm{U}=0,23 \mathrm{~W} / \mathrm{m}^{2} \mathrm{~K}\right)$ for External wall insulation and $8 \mathrm{~cm}$ stone wool $\left(\mathrm{U}=0,65 \mathrm{~W} / \mathrm{m}^{2} \mathrm{~K}\right)$ for Internal wall insulation. For ETICS and External wall insulation these thicknesses generate U-values that are almost the same as the EPB-requirement $\left(\mathrm{U}_{\max }=0,24\right.$ $\mathrm{W} / \mathrm{m}^{2} \mathrm{~K}$ ), which is logical since the EPB requirements are based on cost optimal level studies. For the Internal wall insulation the same conclusions as with the LCA are valid: it is not possible to create low U-values with this construction method and thus to create valuable conclusions for this sub-study another dynamic construction method should be developed.

It is clear that the LCC study results in much lower optimal insulation thicknesses than the LCA study. This phenomenon can be explained by looking more into detail at the contribution of the different life cycle phases to the environmental score and financial cost. In Figure 6 this is done for External wall insulation $12 \mathrm{~cm}$ PUR. The figure shows that for the environmental score the operational energy has the largest share, something that was already concluded based on Figure 3. For the financial cost the operational energy is far less important and the initial investment cost generates the largest impact. Because the operational energy is far less dominant for the financial cost than for the environmental score the use of extra insulation (extra initial investment) to generate energy savings will not be as beneficial. This will result in much lower optimal insulation thicknesses in the LCC calculations.

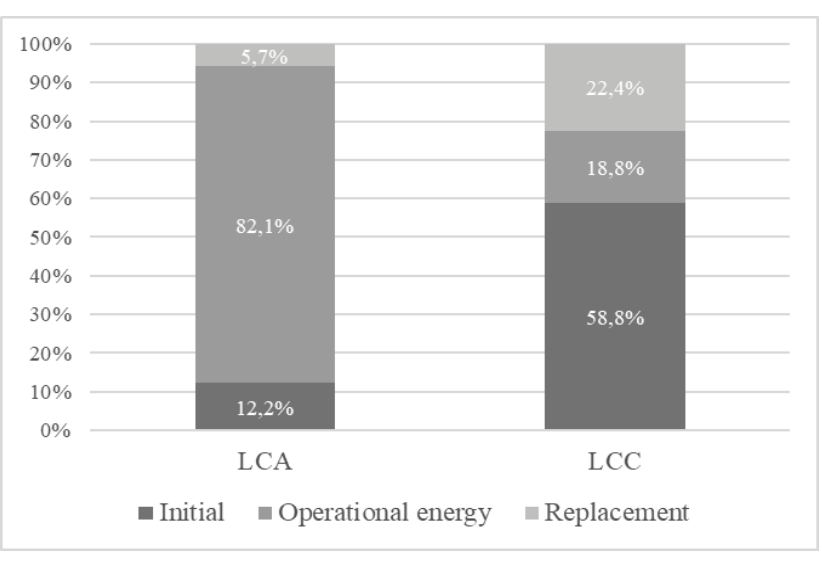

Fig. 6. Contribution life cycle phases.

\subsection{Comparison wall constructions}

The wall constructions that were compared in the LCA study, are now ranked financially. Figure 7 shows the NPV of the different wall constructions. The differences with the LCA ranking are to a large extent the consequence of the fact that energy efficiency measures don't have the same importance financially as they have environmentally. Cavity wall insulation scores the best because with only a small investment (material addition) significant energy savings can be reached in comparison to the Baseline scenario. While from an environmental perspective ETICS 40 scored better than the actual executed renovation (ETICS 27), from a financial perspective the actual renovation scores better. So achieving the environmental optimum does have an additional financial cost. For a person to strive to the environmental optimum there should be an ideological incentive or a financial incentive from the government in the form of subsidies. From the environmental point of view it always had a positive impact to renovate. From the financial point of view not renovating is better than the application of internal wall insulation for this case study (Figure 7).

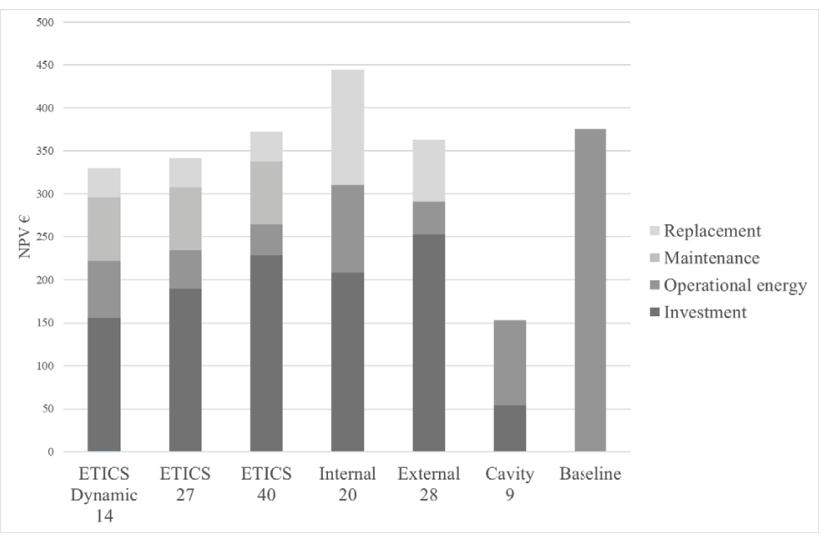

Fig. 7. NPV wall constructions after 60 years.

The maintenance cost of ETICS has a significant impact because of the extensive maintenance plan required (10 years after installation the first maintenance is needed, after that the maintenance should be carried out every 5 
years. After 30 years the plaster should be replaced) [20]. This proves the importance of taking the whole life cycle into account to determine the true financial cost of a renovation decision. Although the investment cost of ETICS can be lower than other strategies, the life cycle costs may be higher. For the LCA ETICS 40 scored better than External wall insulation, for the LCC this is no longer the case because of the high maintenance cost of ETICS.

\subsection{Optimal façade construction}

Triple glazing gave the best environmental score, but the difference with double glazing was relatively small. What does it financially mean to go from single, to double and triple glazing? The LCC study shows that with a small difference triple glazing scores financially better than double glazing. Single glazing scores the worst. This is the same order as with LCA.

In the last step of the LCC study the NPV of the different wall-window combinations, which were studied with LCA, are determined. Figure 8 shows the NPV of the different combinations after a life span of 60 years. While from the environmental viewpoint it wasn't clear if it was more beneficial to replace the window or to adapt the wall construction, from financial viewpoint it can be stated that the façades where only the wall was adapted score worse than if only the window was adapted. This is because the replacement of the window is cheaper than adaption of the wall construction, but still important energy savings can be realized. All combinations with Cavity wall insulation give the best score, again because with a relative small investment significant energy savings can be realized.

The actual executed renovation ETICS 27 scores average on LCC while it scored second best on LCA. Both environmental and financial score would have improved if instead of an aluminum window frame a PVC window frame had been used.

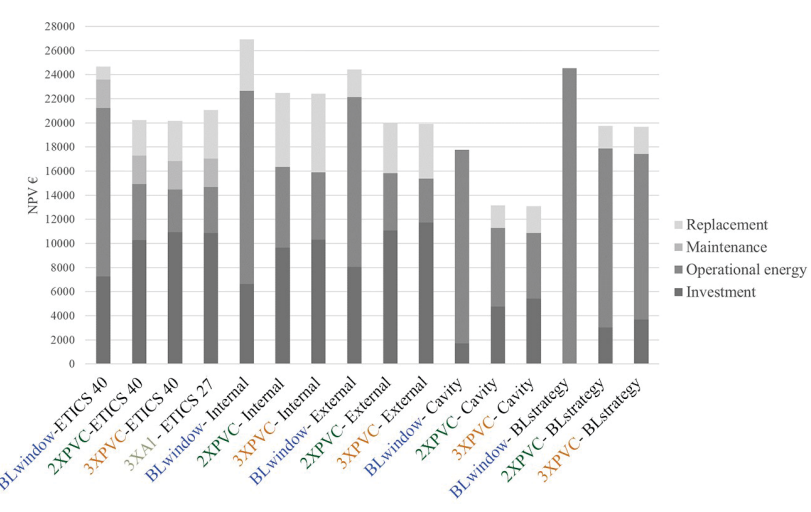

Fig. 8. NPV of façade renovation strategies (wall + window).

\subsubsection{Pareto front optimal façade construction}

A common method used to define the optimum between two criteria, here the environmental and financial criterium, is the Pareto front $[9,21,22]$. All points on the
Pareto front represent combinations that are optimal: there are no other combinations that have a better environmental score for the same NPV and vice versa. For a combined LCA and LCC study this method is often used to find the environmental-financial optimal solutions in a huge range of construction combinations (e.g. different wall types combined with different insulation thicknesses and different window types). This is not the objective of this research and here there are only a limited amount of renovation strategies that can be plotted. In Figure 9 the different façade (wall + window) renovation strategies are plotted. The $\mathrm{x}$-axis represents the NPV, the y-axis the environmental score.

Three strategies lie on the Pareto front: Cavity wall insulation with triple glazed windows, ETICS 40 with triple glazed windows and External wall insulation with triple glazed windows. As was already mentioned the choice for a triple glazed window is financially and environmentally interesting and it is therefore logical that all Pareto optimal solutions contain it. Not renovating or strategies where only the wall construction is adapted or the windows are changed does not result in any Pareto optima.

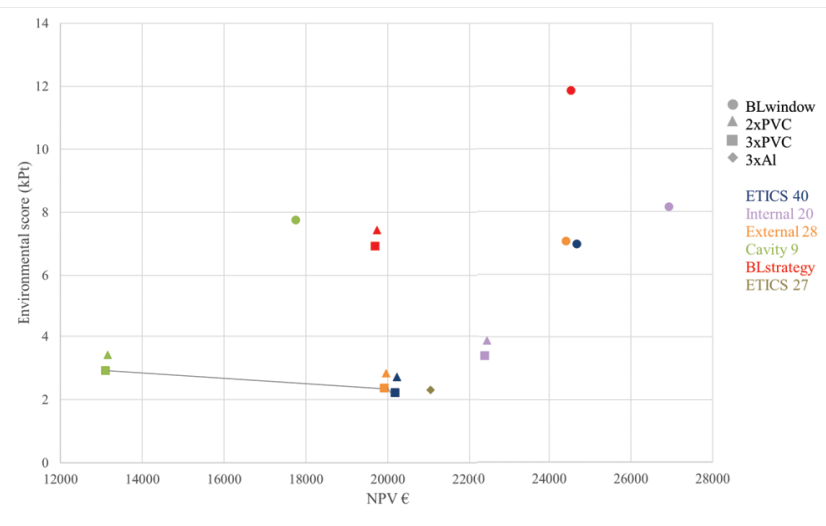

Fig. 9. Pareto front NPV and environmental score.

\subsection{Sensitivity analysis economic parameters}

Because it is difficult to make predictions about the economic situation over the life span of a building it is relevant to perform a sensitivity analysis on the economic parameters real discount rate and real growth rate for energy prices. This illustrates how sensitive the results are to a specific parameter and thus how important the parameter is. For the real discount rate $\mathrm{d}=3 \%$ is chosen, based on the European 'Cost Optimal Levels'-study (EPD 2010/31/EU + corresponding guideline), which states that the real discount rate should at least once be taken at $3 \%$ for macro-economic research calculations [23]. Although this is a microeconomic research, this seems an appropriate guideline to follow for the sensitivity analysis. For the real growth grate it is assumed that energy prices follow the inflation and $\mathrm{g}=0 \%$.

When increasing the real discount rate (from $1,8 \%$ to $3 \%$ ) less importance is given to the future cash flows and the total NPV will decrease. The contribution of the operational energy, maintenance and replacement costs 
will decrease while that of the investment cost will increase. Because of the lowered significance of the operational energy the financial optimal insulation thickness lowers. The order of ranking of the optimal wall constructions remains the same with only the Baseline scenario scoring better. It goes from being second last to second best. This is because the Baseline scenario does not have any investment costs and only future costs (operational energy). This strategy will thus benefit the most from an increased discount rate. For the order of the façade ranking (wall + window) there is some shifting. Again the Baseline scenario scores better. The actual executed renovation scores worse because the aluminum window frame generates a high investment cost.

When the real growth rate for energy prices is lowered (from $1,6 \%$ to $0 \%$ ), the operational energy cost becomes less important. This gives similar results as when the real discount rate was increased: lower optimal financial insulation thicknesses and the Baseline scenario scores better. Figure 10 shows how the contribution of the life phases to the total cost changes for the different scenarios of the sensitivity analysis for ETICS $40 \mathrm{~cm}$.

With a lowered real growth rate also the choice for triple glazing is no longer the best solution and double glazing becomes financially more interesting. The higher the real growth rate, the more beneficial energy saving measures will be. In this sense: the higher the real growth rate the more similar the LCA and LCC results will be. Of course this is not $100 \%$ true since the maintenance and construction phase have different significance for LCA and LCC.

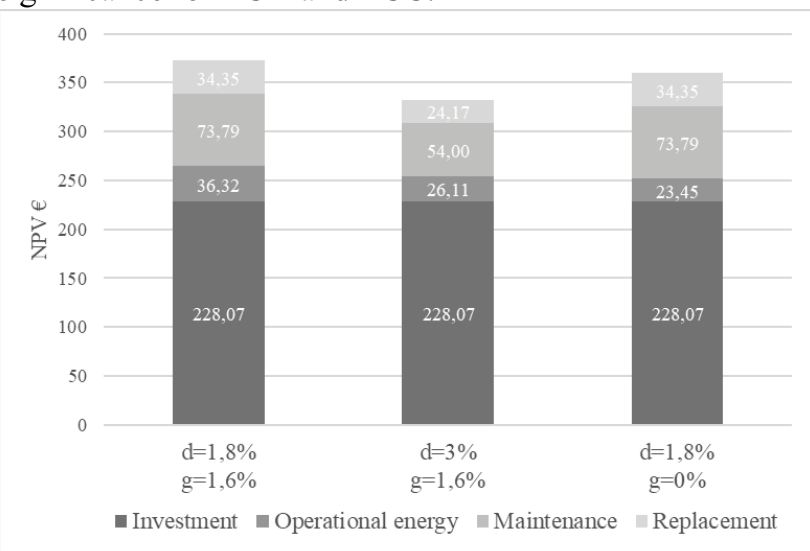

Fig. 10. Contribution of the life phases to the total cost for scenarios sensitivity analysis of ETICS 40 .

\section{Conclusion and remarks}

The exact results of this research are case study specific, but the applied methodology is general. The goal of the research paper was to illustrate how LCA and LCC relate to each other and how decisions based on one or the other may lead to different results. The different contribution of the life cycle phases to the environmental score and financial cost will lead to different motives for reaching the lowest score and cost. For the environmental score the operational energy has the largest share and it will therefore be an important first step to reduce this. The environmental impact from extra energy saving measures (in this research material additions) will be compensated and lead to a lower total environmental score. For the financial cost the initial investment cost will have the highest share and the goal will often be to keep this as low as possible. Extra investments for energy savings only pay off to a certain extent. This effect becomes less strong when the growth rate of energy prices increases and thus the operational energy cost becomes more important. Also the life span taken into account will play an important role. The longer the life span, the more important future costs become towards the investment cost and thus the more relevant energy saving measures.

Although the investment cost has the highest share in the NPV, the importance of taking the whole life cycle cost into account is illustrated by the high maintenance cost of ETICS. Although there were large differences for the optimal insulation thickness between the LCA and LCC, this research illustrates that decisions for material and construction choices for environment and financial can coincide. For example the choice of triple glazing is beneficial from both perspectives. Other examples are illustrated in Figure 5.

In this research first an LCA and then an LCC was executed. A next step is to simultaneously execute the LCA and LCC to obtain a more holistic approach of the evaluation of façade renovation strategies. Now a price tag was put on the environmental optima found through LCA. Integrating both studies from the start will allow to get an environmental-financial optimum and may lead to different results than the ones considered in this study.

For future studies it can be interesting to also integrate the maintenance and construction phase in the LCA studies. Although this should not change the results significantly because of their limited impact it will give more precise results and comparisons.

This research was supported by the VLAIO project 'Living Labs Dwelling Renovation' (IWT/140126). The authors want to give a special thanks to the architecture office B2Ai for providing the specific data on Building IV for this research.

\section{References}

1. European Commission, The European Green Deal, European Commission (2019)

2. E.D. Angelis, P.di Milano, et al., TU Graz p.77-86 (2013)

3. K. Mjörnell, A. Boss, et al., Sustainability, (6), 42274245, July 2014.

4. L. Malmgren, K. Mjörnell, Sustainability, 7(9), 12521-12538 (2015)

5. Zolpan, Gamme Armaterm - Guide de composants. Zolpan (2019).

6. PRé Consultants, 2012. A guide to life cycle costing: https:/www.pre-sustainability.com/ NEWS/LIFECYCLE-COSTING-IN-MORE-DETAIL

7. L. Wijnants, K. Allacker, F. De Troyer, Energy Procedia 96, 529-539 (2016) 
8. Wastiels, L., Grégoire, Y., Milieu-impact van ETICS. WTCB-publication 7 (in Dutch) 2012.

9. K. Allacker, Sustainable building: the development of an evaluation method. K.U.Leuven (2010)

10. M. Delghust, Improving the Predictive Power of Simplified Residential Space Heating Demand Models: a Field Data and Model Driven Study. Ghent University (2016).

11. M. Goedkoop, R. Heijungs, M. Huijbregts, e.a., Recipe 2008 - Report I: characterisation. Ruimte en milieu: Ministerie van Volkshuisvesting, Ruimtelijke ordening en Milieubeheer.

12. BUtgb, 2016. ATG 3059 - Buitengevelisolatiesysteem met pleisterafwerking - ETICS WILLCO. BUtgb (in Dutch).

13. Knauf, 2018. P322 - Knauf gevelisolatie B1 - De kostenbesparende en energie-efficiënte gevel. Knauf (in Dutch).

14. Covarte, 2018. Instructiefolder 2018 - Gevels. Covarte (in Dutch).

15. O. Pombo, B. Rivela, J. Neila, Journal of Cleaner Production 123, 88-100 (2016)

16. Federal planbureau, 2019. Economische vooruitzichten 2019-2024 - versie van februari 2019. Federaal Planbureau (in Dutch).

17. Federal planbureau, 2017. Het Belgische energielandschap tegen 2050 - Een projectie bij ongewijzigd beleid. Federaal Planbureau (in Dutch).

18. ASPEN. (2019a). ASPEN INDEX - Onderhoud, ombouw, editie 53. East-Flanders, Belgium: ASPEN (in Dutch).

19. Eurostat, 2019. Gas prices for household consumers - bi-annual data (from 2007 onwards). Eurostat.

20. C. Decommere, Onderhoud buitenpleister. Willco (in Dutch) (2019)

21. F. Flager, J. Basbagill, et al., Multi-objective building envelope optimization for life-cycle cost and global warming potential. Stanford University (2016)

22. W. Wang, R. Zmeureanu, Building and environment 40, 1512-1525 (2004)

23. European Commission, 2012. Commission delegated regulation (EU) No 244/2012 of 16 January 2012 supplementing Directive 2010/31/EU of the European Parliament and of the Council on the energy performance of buildings. European commission. 